\title{
Maternal Attachment and Preventive Intervention Methods in Mothers Under Covid- 19 Stress
}

\section{Covid-19 Stresi Altındaki Annelerde Maternal Bağlanma ve Önleyici Müdahale Yöntemleri}

\author{
Aslıhan Kurt ${ }^{1}$, Hande Çelikay Söyler ${ }^{2}$
}

\begin{abstract}
:
The aim of this review study is to examine the effects of Covid-19, a global health crisis that paves the way for a great increase in the morbidity of psychological and psychosocial disorders, on mothers in the groups at risk and the role of these effects in the maternal attachment relationship and the methods of coping with it are discussed within the framework of the literature. In addition to the life change and anxiety that comes with being a parent, the fear of contagion and uncertainty can negatively affect women's emotional well-being and cause anxiety. Sometimes mothers find it difficult to relate to their babies due to environmental factors such as stress, and such failure can have long-term effects on the baby. Considering that the pandemic period is a major source of stress in itself, it is predicted that the bonding process of mothers with their babies will be affected by the epidemic. In light of this information, healthcare providers and policy makers should be aware of the possible long-term impact on women and children of the significant burden of psychological morbidity during the perinatal period among Turkish women. Implementation of effective screening and intervention programs can help improve perinatal mental health and improve the quality of postnatal care in Turkey.
\end{abstract}

Keywords: Covid-19, maternal attachment, preventive intervention methods

${ }^{1} \mathrm{MSc}$, Faculty of Arts and Sciences, Psychology Department, Near East University, Nicosia-Cyprus, Orcid İd: 0000-0002-5241-127X

${ }^{2}$ Asst. Prof., Faculty of Arts and Sciences, Psychology Department, Near East University, Nicosia-Cyprus, Orcid İd: 0000-0001-6735-1321

Address of Correspondence/Yazışma Adresi: Faculty of Arts and Sciences, Psychology Department, Near East University, Nicosia- Cyprus, E-mail: aslhan_kurt@yahoo.com.tr

Date of Received/Geliş Tarihi: 23.09.2021, Date of Revision/Düzeltme Tarihi: 16.10.2021, Date of Acceptance/Kabul Tarihi: 20.10.2021, Date of Online Publication/Çevirimiçi Yayın Tarihi: 01.12.2021

Citing/Referans Gösterimi: Kurt, A. \& Çelikay-Söyler, H. (2021). Maternal Attachment and Preventive Intervention Methods in Mothers under Covid-19 Stress, Cyprus Turkish Journal of Psychiatry \& Psychology, 3(4): 304-313

(C) 2021 The Author(s). Published by Cyprus Mental Health Institute / Cyprus Turkish Journal of Psychiatry and Psychology (www.ktppdergisi.com). This article is an open access article distributed under the terms and conditions of the Creative Commons Attribution 4.0 license which permits use, sharing, adaptation, distribution and reproduction in any medium or format, provided the original work is properly cited and is not used for commercial purposes. http://creativecommons.org/licenses/by/4.0/ 


\section{Öz:}

Bu derleme çalışmasının amacı, psikolojik ve psikososyal bozuklukların morbiditesinde büyük bir artışa zemin hazırlayan küresel bir sağlık krizi olan Covid-19'un risk altında olan grupların içinde yer alan anneler üzerindeki etkileri ve bu etkilerin maternal bağlanma ilişkisindeki rolünün incelenmesi ve bununla baş etme yöntemlerinin literatür çerçevesinde tartışılmasıdır. Ebeveyn olmanın getirdiği yaşam değişikliği ve endişeye ek olarak bulaşma korkusu ve belirsizlik kadınların duygusal refahını olumsuz etkileyerek endişeye neden olabilir. Bazen anneler stres gibi çevresel faktörlerden dolayı bebekleriyle ilişki kurmakta zorlanır ve bu tür bir başarısızlığın bebek üzerinde uzun vadeli etkileri olabilir. Pandemi döneminin başlı başına büyük bir stres kaynağı olduğu düşünüldüğ̈̈nde annelerin bebekleriyle bağ kurma sürecinin salgından etkileneceği öngörülmektedir. Bu bilgiler 1şı̆̆ında sağlık sağlayıcıları ve politika yapıcılar, Türk kadınları arasında perinatal dönemdeki önemli psikolojik morbidite yükünün kadınlar ve çocuklar üzerindeki olası uzun vadeli etkisinin farkında olmalıdır. Etkili tarama ve müdahale programlarının uygulanması Türkiye'de perinatal ruh sağlığının geliştirilmesinde ve doğum sonrası bakımın kalitesinin iyileştirilmesine yardımcı olabilir.

Anahtar Kelimeler: Covid-19, maternal bağlanma, önleyici müdahale yöntemleri

\section{Giriş}

Bağlanma teriminin kökeni 13. yüzyıla uzanmaktadır. Bağlanma fiilinin etimolojik anlamı bir yere bağlanmak veya oturmak/yerleşmektir. 18. yüzyılın Fransız yazar ve filozofu Rousseau; bağlanma kavramını anne- bebek ilişkisi ile ilgili kullanan ilk kişidir. Bağlanma hakkındaki yazıları anne sevgisiyle ilgiliydi. Bağlanmanın kökeni annelerin bebeğinin uyku ya da uyku-uyanma döngüsü gibi özelliklerini tanımayı, bebekleriyle iletişim kurmayı ve ona sevgi geliştirmeyi öğrendikleri ipucu duyarlılığ olarak tanımlanmıştır (Goulet, Bell, Tribble, Paul ve Lang, 1998). 1969'da Bowlby bağlanmayı iki kişi arasındaki güçlü bir bağ olarak tanımladı ve kavramın evriminde bir kilometre taşı oldu. Bağlanma sürecini sadece çocuktan ebeveyne doğru tanımlamasına rağmen tanımı ebeveynin de bebeğe olan bağlanma sürecini de içerecek şekilde karşılıklı bağlanma sürecini açıklığa kavuşturmaya yardımcı oldu. $\mathrm{Bu}$ perspektiften yapılan araştırma ebeveynine güvenli bağlanan bir bebeğin sağllklı bir özimaj gelişimini desteklediğine ve sonraki yaşamdaki ilişkileri etkilediğine dair kanıt sağlamıştır. Bir annenin bebeğinin sinyallerine ve ihtiyaçlarına yaşamın ilk yıllarında duyarlı bir şekilde yanıt vermesi bağlanmanın ön koşuludur. Bebeğinin ağlamalarına tepki vermede yavaş veya tutarsız olan, düzenli olarak bebeğinin istediği faaliyetlere müdahale eden veya mecbur hissettiği için kendini bebeğe şefkat göstermeye zorlayan anneler normalden daha fazla ağlayan, daha az keşif yapan bebekler üretir. Bebek bağlanma davranışlarını aşırı öfke ifadeleriyle karıştırır. Eğer anne sürekli endişeli görünürse, bebeğin fiziksel temas kurma girişimlerini reddederse bebek ondan kaçınmayı öğrenebilir (Bowlby, 1988). Annenin duyarlılı̆̆ı çocuğun güvenli bağlanma geliştirmesini sağlar. Güvenli bağlanmanın yaşamın erken dönemlerinde gelişimi çocuğun kendilik ve başkalarına ilişkin temsillerini etkileyen önemli bir gelişimsel dönemdir. $\mathrm{Bu}$ kendisinin ve başkalarının gelecekteki beklentilerini etkileyerek bağlanma ile ilgili düşünce ve duyguları işleme stratejilerini belirler. Güvensiz bağlanma stratejileri ya bağlanma ifadesini en aza indirmeyi (kaçınan tarzlar) ya da bu tür bir ifadeyi en üst düzeye çıkarmayı (endişeli/birbirine geçmiş tarzlar) içerir. Bu stratejiler sırasıyla uzak, içedönük veya müdahaleci ve cezalandırıcı olarak tanımlanan annelik davranışlarıyla ilgilidir. Sosyal olarak sıkıntılı veya stresli koşullarda yaşayanlarda daha sık görülür. Yapılan bir çalışmada maternal bağlanma stilinin doğumla ilişkili depresyonu yordadığına dair sonuçlar ortaya çıkmıştır. Güvensiz bağlanma tarzı daha düşük sosyal sınıf, işsizlik, daha az sosyal desteğe sahip olma, daha az sosyal ilişki gibi daha olumsuz sosyal koşullarla ilişkili bulunmuştur. Uzun vadede annenin maternal bağlanma stilinin özellikle güvensiz bağlanmanın doğum sonrası depresyona karşı anneyi savunmasız hale getirdiğine dair çalışmalar yapılmıştır (Bifulco ve ark., 2004). Bağlanmada iki önemli değişken vardır. Bunlar; bağlanma figürünün genel destek ve koruma çağrılarına yanıt vermesi ve bağlanma figürünün yanıt vereceğinin düşünülmesi/yanıt vermesinin muhtemel olduğu türden bir kişi olarak değerlendirilip değerlendirilmediğidir (Hazan ve Shaver, 1987). Bebeklerin bağlanma figürleri olmadığında 3 tepki gösterirler. Bu tepkiler; ağlayarak durumu protesto etmek, umutsuzluk ve yas tepkileri, bağlanmanın çözülmesidir (Hazan ve Shaver, 1994). Buradan yola çıkarak maternal bağlanmanın nesilden nesile aktarılarak gerekli farkındalığa erişilmedikçe bir kısır döngü halinde devam edebileceği düşünülmektedir. $\mathrm{Bu}$ nedenle gelişim evresinin kritik bir adımıdır. Klinisyenler ve gelişimciler tarafindan bağlanma örüntülerinin kuşaklar arası aktarımı hala araştırılmaktadır.

\section{Yöntem}

Bu çalışma geleneksel derleme olacak şekilde yazılmıştır. Çalışma konuyla ilgili Türkiye'de ve dünyada yapılmış olan çalışmaların taranması biçiminde gerçekleştirilmiştir. Sistematik olmayan bir inceleme; bir konuyla ilgili literatürün her şeyi kapsayan değil, bilgilendirici bir incelemesi olması amaçlanan sistematik olmayan bir literatür taramasıdır. Bu araştırma türü genellikle belirli bir araştırma sorusuna derinlemesine, fakat sistematik olmayan bir yaklaşım benimser (Huelin, Iheanacho, Payne ve Sandman, 2015). Literatürde Covid-19 döneminde anne-bebek bağlanması, anne-bebek bağlanmasını arttırmaya yönelik önleyici müdahaleler anahtar sözcükleriyle arama yapılmıştır. 


\section{Salgın Döneminin Bağlanma Üzerindeki Etkisi}

COVID-19 virüsü, SARS-CoV ve MERS-CoV'unda içine bulunduğu betacoronavirus (beta- koronavirüs) ailesi içinde yer alan bir virüs türü olup, 2019 yllında ortaya çıkıp kısa zaman içerisinde hızla tüm dünyayı etkisine almış ve durum küresel bir salgın yani "pandemi" olarak ilan edilmiştir (World Health Organization, 2020). Başlıca solunum yolu enfeksiyonuna neden olan bu virüs bireylerin sadece fiziksel sağlığını tehdit etmekle kalmayıp aynı zamanda ruhsal sağlık üzerinde de hem akut hem de uzun vadeli etkiler ortaya çıarabilmektedir. Özellikle salgının ortaya çıkışı ve vaka sayılarının arttığ dönemlerde bireylerin artan düzeyde korku, endişe ve stres algıladığı gözlenmiştir. Yeni doğanlar; bağışıklık sistemi olgunlaşmamış, ancak vajinal doğumlar sırasında dışkı ve idrar yoluyla perinatal temas olasıllı̆̆ ve doğumdan sonra asemptomatik olarak enfekte anne ile yakın temas nedeniyle kanıtlanmamış maternal dikey geçiş yüksek risk grubunda yer almaktadır. Pandemi sürecinde hasta ile en fazla vakit geçiren ebe / hemşirenin sürekli kendini geliştirmesi ve bilgilerini güncellemesi büyük önem taşımaktadır (Çuvadar ve Çuvadar, 2021). Pandemi süreci anne adaylarının da içerisine alan korku ve kaygı yüklü bir süreç haline gelmiştir. Doğum sonrası aileye yeni bir üyenin gelmesiyle hem ilişkilerde hem de yaşam tarzında bir takım duygusal değişimler yaşanır (Arslan ve Uzun, 2008). Bu değişimlerle birlikte yeni rol ve sorumluluklar anne veya anne adayı için zorlayıcı bir dönem olabilir. Doğum sonrası dönemde annelerin bebekle ilgili algıs1, anne-bebek bağlanmasının temelini oluşturur. $\mathrm{Bu}$ bağlanma bebeklerin gelecekteki yaşamlarını olumlu etkileyen, sağlıklı bir şekilde büyümesini sağlayan önemli bileşenlerden biridir (Adam, Gunnar ve Tanaka, 2004). Özellikle duyarlılık, kabul, işbirliği ve erişilebilirlik güvenli bağlanma ile ilişkili bulunmuştur. Anne davranıșının en önemli yönünün genellikle bebeğin güvenlik-kaygı boyutlarıyla ilişkili olduğu sonucuna varılmıştır. Anneler duygusal olarak belirgin ipuçlarını algilama ve bunlara tepki verme yeteneklerinde kısmen kendi geçmişlerinden dolayı farklılık gösterebilirler. Bağlanma temsilleri veya içsel bağlanma modelleri, geçmiş bağlanma ile ilgili deneyimler hakkındaki annenin düşüncelerini ve duygularını yansıtarak önemli ilişkileri sürdürmek ve bağlanma hedeflerini gerçekleştirmek için stratejileri şekillendirir. $\mathrm{Bu}$ temsiller duygu düzenlemesinin doğasını, başkalarının tepkilerinin değerlendirilmesini ve annelerin kendi tepkilerini etkiler. Bu nedenle anneye özgü bağlanma temsilleri anne-bebek etkileşimleri sırasında duygunun işlenmesini ve ifade edilmesini sınırlayabilir (Alhusen, 2008). Bağlanma ilişkilerine değer veren ve bu ilişkilerdeki deneyimleri etkili olarak gören annelerin bağlanmaya ilişkin güvenli zihin durumlarına sahip oldukları kabul edilmektedir. Bu annelerin bebekleriyle etkileşim halindeyken çeşitli bebek duygularıyla ilgilenme, olumsuz duyguları kabul etme ve duygu düzenlemede yardım sağlama konusunda tutarlıdır. Ayrica güvenli bebeklerin anneleri bebeklerin duygu durumuna da duyarlıdır (Milligan, Atkinson, Trehub, Benoit ve Poulton, 2003). Bazen anneler stres gibi çevresel faktörlerden dolayı bebekleriyle ilişki kurmakta zorlanır ve bu tür bir başarısızlığın bebek üzerinde uzun vadeli etkileri olabilir. Pandemi döneminin başlı başına büyük bir stres kaynağ 1 olduğu düşünüldüğünde annelerin bebekleriyle bağ kurma sürecinin salgından etkileneceği öngörülmektedir. Bebeklerin bilişsel ve davranışsal gelişimi için özellikle birincil bakıcılarla erken dönem ilişkilerinin önemi artık iyice bilinmektedir. Bebeklik ve çocukluktaki anne sevgisi fiziksel sağlıktaki vitaminler ve proteinler kadar zihinsel sağlık için önemlidir (Taylor, Atkins, Kumar, Adams ve Glover, 2005). Yapılan bir araştırmada annenin ruhsal durumunun ve stres yaşamasının anne-bebek ilişkisinde bozukluğa ve bebek üzerinde uzun süreli bir etkiye neden olacağı belirtilmiştir. Eğer sorun tespit edilebilirse müdahale yöntemlerinin olduğu vurgulanmıştır (Brockington, 2004). Sağlıklı bir anne bağlanmasında; annelerin yeni role uyum sağlaması, zorluklarla baş edebilmek için destek alması önemlidir. Bu destekler biçim itibariyle kültürden kültüre farklılık gösterse de başa çıkmayı etkileyerek stres kaynağı ile sonuç arasındaki gidişatı değiştirebilir. Akraba ve arkadaşlardan alınan destek hamilelik ve sonrasında önemli bir rol oynar. Literatürde eşiyle uyumlu ve yeterli destek alan annenin daha az sorun yaşadığı, çiftler arası uyumsuzluk, yetersiz sosyal destek ve stresli yaşam koşulları yaşayan annelerin ise daha fazla psikiyatrik sorun yaşadığ bulunmuştur (Callister, Beckstrand ve Corbett, 2011). Yapılan bir diğer araştırmada da doğum sonrası dönemde anneye bağlanmayı olumsuz etkileyen faktörler; anne-baba arasındaki uyumsuzluk, sosyal güvencenin olmaması, sağlık sorunları, sosyal destek azlığı, yaşanan stres, travma, afet ve toplumsal olaylar olarak bulunmuştur (Alan ve Ege, 2013). Anne-bebeğin karşılıklı etkileşimi, annenin bebeğin ihtiyaçlarını karşıladığı, bebeğin işaretlerini tanıdığı, uyum sağladığ zaman içinde gelişen bir süreçtir. Bu etkileşime etki eden faktörler; annenin yeni rolüne uyumu, aldığı sosyal destek ve stres önemlidir (Amy, 2008). Bebek ile fazla temasın da bağlanma davranışlarını artırdığı bulunmuştur (Kavlak ve Şirin,2007). İçinde bulunduğumuz bu salgın döneminde bebeklerin temizliğine ekstra özen gösterilmekte bu da birincil bakım verenin bebeğe daha temkinli yaklaşmasına sebebiyet verebilmektedir (Özcan ve Elkoca, 2020). Dolayısıyla temasların eskisi kadar yoğun ve rahat olamaması anne-bebek ilişkisini etkileyebilir. COVID-19 sürecinde emzirmenin endişe, korku, panik, hemşire ve ebe desteğinin yetersiz kalması gibi nedenler ile bırakılması ve formüle mama seçilmesi ile anne-bebek etkileşimi zedelenmektedir. Bu zedelenme sonucunda, anne ve bebek arasında davranışsal sinyallerin doğru algılanmaması, güvensizlik, huzursuzluk bulguları ortaya çıkmaktadır. Sosyal destek eksikliğine ek olarak pandemi döneminde doğumların tüm ailenin birlikte bebeği karşıladığı, hastane odalarının süslendiği, ikramlıkların hazırlandığı bir kutlama yerine tek başına yabancılarla dolu bir odada yapılan sancıl1, acılı ve endișe verici bir olaya dönüşmesi annelerin kaygısını ve depresyonu tetikleyebilir. Annenin alışık olmadığı, düzeninin olmadığ 1 yabancı bir hastane odasında olmasının bile bağlanmayı etkilediği bilinmektedir (Arslan, Keleş ve Arık, 2021). Bu süreçte babanın anneyi nasıl etkilediği ve bunun bağlanma ile bağlantısına bakıldığında annelik rolüne uyumda özgüven ve prenatal dönemde başlayan sosyal destek arasında pozitif bir ilişki olduğu, eşi tarafından onaylanan ve sorunlarını eșiyle paylaşabilen kadınların daha az sorun yaşadıkları yapılan bir çalışmada belirtilmiştir (Çakır ve Can, 2012). Başka bir çalışmada da gebelikte yakınları tarafından sağlanan sosyal desteğin, bilişsel ve duygusal olarak rahatlamaya, stres ve kaygı ile baş etme mekanizmalarını güçlendirmeye ve annelik rolüne geçişi kolaylaştırarak daha doyumlu bir gebelik dönemi yaşanmasında etkili bir faktör olduğu bulunmuştur (Elsenbruch ve ark., 2007). Bu nedenlerle gebelikte sosyal desteğin anne-bebek bağlanmasını artırabileceği 
düşünülmektedir. Salgın önlemleri kapsamında hastanelere ulaşımın kısıtlanması annenin bebeğini ultrasonda görüp kalp atışını duyamaması bebeğini hissedememesine, yeni doğan bebeğinin kontrolleri için endişe yaşamasına neden olabilir. Hamilelik sırasında ultrasonun kullanılması, fetüsün görsel görüntüsünün maternal bağlanma üzerindeki etkisi incelenmiş ve fetüsün bu erken görünüşünün annenin onu küçük bir insan olarak ayırt etme yeteneğini geliştirdiği bulunmuştur (Brandon, Pitts, Denton, Stringer ve Evans, 2009).

\section{Anne Bebek Bağlanmasını Artıracak Önleyici Müdahaleler}

$\mathrm{Bu}$ dönemde annenin bedenindeki ve zihnindeki birtakım değişiklikler strese ve endişeye neden olabilir. Bu zihinsel değişiklikler anormalleşirse, uzun vadede bazı zihinsel baskılar ortaya çıkacak ve çok stresli bir dönem yaratacaktır. Çeşitli müdahaleler ile anne-bebek bağlanması artırılabilir ve bu dönemde ortaya çıkabilecek psikolojik semptomlar önlenebilir (Mckee, Cunningham, Jankowski ve Zayas, 2001). Gebelik ve emzirme döneminde ilaç reçetelerine ilişkin bazı sınırlamalar olduğundan perinatal döneme bağl1 anksiyete ve depresyonu önlemek ve iyileştirmek için farmakolojik olmayan yöntemler odak noktasıdır. Bu müdahalelerden biri anne-fetüs/bebek bağlanma becerilerini artırma eğitimidir. Anne-fetüs etkileşimi daha düşük anksiyeteye neden olabilir. Bebeğe artan maternal duyarlılık ile etkili ve yeterli bakım sağlanabilir (Sercekus ve Baskale, 2016). Tüm bu stresörlerle birlikte olağan başa çıkma stratejilerine erişimin azalması salgın sırasında anksiyete geliştiren perinatal kadınlar için riski artırmaktadır. Farkındalık temelli Bilişsel Davranışçı Terapi (BDT) uygulanabilir. Bağlanma davranışı eğitiminin kaygıyı azalttığ1 ve anne-bebek bağlanmasını $\operatorname{artırdığ1~da~}$ bulunmuştur (Neff, 2009). Gebelik sirasında mevcut olan semptomların başarılı bir şekilde yönetilmesinin doğum sonrasi psikolojik duygu durumun ve anksiyete bozukluğunun azaltılmasına yardımc1 olabileceği bulunmuştur (Buist ve ark., 2002). Bir diğer çalışmada grupla psikolojik danışmanın planlanmamış gebelikte bağlanmayı iyileştirici etkisi bulunmuştur (Jangjoo, Lotfi, Assareh ve Kabir, 2019). Bu doğrultuda bağlanma eğitim atölyeleri ve iletişim becerileri eğitimi düzenlenebilir, doğum öncesi dönemde grup çalışmaları yapılabilir. Yapılan başka bir çalışmada ise bilişsel yaklaşıma dayalı ebelik danışmanlığı istemeden gebe kalan kadınlarda bağlanma ve yaşama uyum kalitesini artırmada etkili bir yaklaşım olduğu bulunmuştur (Sedgh, Singh ve Hussain, 2014).

Doğum öncesi bakım alan annelerde bağlanma puanlarının daha yüksek olduğu tespit edilmiştir (Bilgin ve ark., 2020). Buradan hareketle doğumdan önce düzenli kontrollerinin yaptırılması, doğum öncesi ve sonrası dönemde yaşanabilecek sorunların azaltılması anne-bebek bağlanmasını olumlu yönde etkilemektedir. Ayrıca hamilelik sırasında doğum ve doğum sonrası bakım hakkında bilgi alan anneler, doğumdan sonra bebeklerine daha iyi bağlanmaktadır (Öztürk ve Saruhan, 2013). Bunlar göz önüne alındiğında hamilelikte ve doğum sonrası dönemde anksiyetenin olumsuz sonuçları ile ilgili olarak annelerin ruh sağlığını iyileştirmek için güvenli, düşük maliyetli ve kolaylık sağlayan bir teknik bulmak önemlidir. Literatürde öne çıkan teknikler;
Fetüsle Illetişim Teknikleri: Anneye karnına nasıl dokunacağını öğretmek, fetüsü tanımak, hareketleri saymak ve kaydetmek, onunla konuşmak, fetüsü takma/ismiyle adla çağırmak, karnına bakmak, fetüse odaklanmak ve onu bağımsız bir kimlik olarak tanımak, organlarının pozisyonlarını tahmin etmek, karnına dokunarak onu sakinleştirmek bu esnada da zihinsel imgeleme uygulamasının yapılması gibi davranışlar annenin duygularını harekete geçirerek fetüsle olan etkileşimi artıracak ve bağlanma üzerinde olumlu bir etkiye yaratacaktır (McNamara, Townsend ve Herbort, 2019). Annenin karnına dokunarak bebeğini hissetmesi bebeğin kabulü ve bağlanma ilişkisi açısından da önemlidir. Zihinsel imgelem eşliğinde karına dokunma eğitimi verilebilir. $\mathrm{Bu}$ eğitim anksiyete üçgeninin ikinci yanına yanı engelli bir bebek doğurmaktan korkan annede etkilidir. Fetal iletişim dolaylı olarak anneyi bedensel değişikliklerden korkmamak için dikkatini dağıtarak anksiyete üçgeninin üçüncü tarafını etkiler. Fetüsün ve emzirirken kendi görünümüne ilişkin olumlu imgeler ile fetal iletişim teknikleri gruplar arasında psikolojik sağlık ve bağlanma açısından anlamlı bir farklılığa neden olmuştur. Bunun yapıldığı grupta bağlanma puanı artış göstermiş, anksiyete puanı ise azalmıştır (Abasi, Tafazzoli, Esmaily ve Hasanabadi, 2013). Ayrica hareketlere odaklanma, fetüsle konuşma, yönlendirmeli imgeleme, karnına dokunma gibi fetal etkileşim tekniklerinin bağlanma artışında ve anksiyetenin azalmasında eğitici etkisi bildirilmiştir (Bellieni ve ark., 2007). Bağlanmanın kalitesi kaygı düzeyini belirler (Faisal ve Menezes, 2007). Hamileliğin neden olduğu kaygının arkasındaki ana nedenler; doğum yapmaktan korkmak, engelli/anormal bir bebekten korkmak ve bedensel değişikliklerden korkmak sayılabilir. Bu kaygının zirvesi hamileliğin ortasındadır. Gebeliğin neden olduğu kaygının nedenlerini açıklayan üç boyutlu model, bağlanmanın eğitici içeriğinin bu üçgenin yanlarını etkili bir şekilde kaplayabildiğini göstermektedir. Bağlanma ile ilgili eğitim içeriklerinden biri de doğum sürecine, fetüs gelişim sürecine aşinalık ve gebeliğin neden olduğu fizyolojik değişiklikleri açıklamak ve algılamaktır (Matthey, Barnett, Howie ve Kavanagh, 2003). Böylece anneleri bu süreçten haberdar etmek, anksiyete üçgeninin üç yüzünü de kapsayarak kaygı üzerinde olumlu bir etki yaratabilir. Yapılan bu çalışmada da annenin bilgi ve farkındalığının artırılması annelerin psikolojik sağlığının artmasına eşlik etmiştir Maternal bağlanma annenin gebelik sürecinde algıladığı stres, psikolojik travmalar ve anksiyete durumu gibi faktörlerden de etkilenmektedir. Annenin anksiyete düzeyinin yüksek olması durumunda anne-bebek arasında kurulan maternal bağlanma düzeyinin de düşük olduğu bulunmuştur (Hart ve McMahon, 2006).

Ultrason Danışmanlığ $:$ : 4 aşamada gerçekleştirilebilir. 1. Fetüsün fiziksel özellikleri, cinsiyeti ve konumu gösterilir, 2. Rahimdeki fetüsün fiziksel hareketleri, refleksi ve yönelim değişiklikleri araştırılır, 3. Annenin gülme, karına bastırma, fetüsle konuşma ve onun için şarkı söyleme gibi eylemlere verdiği tepkileri keşfetmesine izin verilir, 4 . Danışma seansı sonrası anne sorgulanır. Bu tekniğin uygulandığı müdahale grubunda bağlanma puanları artmış ve ortalama kaygı azalmıştır. Ultrason kullanılmasının ve gebelerin bilgilendirilmesinin maternal bağlanma üzerinde olumlu etkisi olduğu kanıtlanmıştır (Boukydis ve ark., 2006). Yapılan bir çalışmanın sonuçları, erken gebelikte ve anne gebelik belirtilerini anlamadan önce sonografi yoluyla embriyonik görüntülerin sunulmasının, annelerin 
anne karnındaki gerçek yaşamı algılamaları için güven verici bir önem taşıdığını ve doğmamış bebeğe olan yoğun bağlanma duygularıyla sonuçlandığını ve gebelikte anne sağlığını artırdığını ortaya koymuştur (Dykes ve Stjernqvist, 2001). Gebeliğin erken döneminde fetüsün görüntülenebilmesi maternal fetal ilişkinin erken dönemde kurulmasına katkı sağladığı yorumu yapılabilir.

Zihinsel Imgeleme: Bebeği kucağında hissederek hayal etmeyi, annelik rolü imgelemine rehberlik etmeyi, emzirirken kendini görselleştirmeyi ve fetüsün görünümünü olumlu olarak görmeyi içerir. Bir çalışmada annelere fetüsün görünüşünün olumlu hayal gücü, yeni doğana sarılıp emzirilmesi ve fetüsle iletişim becerileri hakkında eğitim verildi. Müdahale grubunun kayg1 düzeyinin önemli ölçüde düştüğü bulunmuştur. Zihinsel imgeleme ve farkındalık artı̧̧ı eşliğinde rahatlama eğitimi üzerinde çalışıldığında ise anksiyete ve bağlanma düzeylerinde anlamlı bir farklılık bulunmuştur (Bussel Van, Spitz ve Demyttenaere, 2009).

Gevşeme: Kas gevşeme tekniği ve nefes egzersizlerini içeren gevşeme eğitimi de etkili bir tekniktir (Smith ve ark., 2018). Zihinsel gevşeme, fetüs üzerinde yoğunlaşma ve bağlanma hakkında olumlu imgeleme için uygun ve etkili bir firsattır. Doğru gevşeme ile birlikte annenin kan dolaşımı ve beyin fonksiyonu iyileşerek artar. Bu olumlu tutum annenin stresini ve anksiyetesini azaltır (Urech ve ark., 2010). Yapılan bir araştırmada bir grupta gebelik sırasında sadece gevşeme eğitimi uygulanmış diğer grupta ise bağlanma davranışları, gebeliğin neden olduğu psikolojik ve fiziksel değişiklikler, bağlanma ve iletişim becerileri, doğum eylemi ve süreci hakkında genel bilgi verilerek babanın destekçi rolüne aşina olduğu bildirilmiştir. Anksiyete düzeyi açısından hem rahatlama hem de eğitim grubu kontrol grubu ile anlamlı bir farklılık ortaya çıkarmıştır. Ancak sadece gevşeme eğitimi verilen grup tek başına kaygıda etkili bulunurken, bağlanma da anlamlı bir fark bulunmamıştır. Anneye bağlanmanın müzik, egzersiz ve eğitici kitap okumaya dayalı birleşik bir planla desteklenebileceği bildirilmiştir (Akbarzadeh, Dokuhaki, Joker, Pishva ve Zare, 2016). Bu doğrultuda diğer yöntemlerle bütünleşik olarak gevşeme tekniklerinin annede bağlanmayı artırmada ve anksiyeteyi azaltmada etkili olduğu söylenilebilir.

Bebekle Fiziksel Temas: Doğumdan hemen sonra anneyeni doğan cilt teması veya cilt yakınlığını, meme emme, anne-yeni doğan odasına alma, yeni doğan dokunuşu ve masajı, yeni doğanı vücuda yakın tutma, sarılma ve öpmeyi içerir. Bir çalışmada cilt teması günde 20-30 dakika yapılmıştır. Kontrol grubuyla bağlanma ve anksiyete bakımından önemli bir fark ortaya çıkmıştır (Gabriel ve ark., 2009). Yeni doğanın ilk iletişim aracı olan dokunma çevresi ile ilişki kurabilmek için faydalanabileceği en gelişmiş duygusudur (Feldman, 2007). $\mathrm{Bu}$ nedenle anne-bebek bağlanmasının geliştirilmesinde en etkili ve doğal dokunma yöntemlerinden birisi de masajdır. Dokunma ve masaj bebeğin vücut temasını sürdürerek güven duygusunu güçlendirir ve annenin bağlanma duygusunu da destekler (Moore, Anderson, Bergman ve Dowswell, 2012). Yapilan bir çalışmada bebek masajının anne-bebek iletişimini güçlendirdiği bulunmuştur (Diego ve ark., 2007). Dolayısıyla doğum sonrası dönemde ebe ve hemşirelerin dokunma duyusu hakkında anneleri bilgilendirmeleri ve teşvik etmeleri önemlidir.
Hamilelik Dönemi Ĕ̆itimi: Gebelikte, gebelik ve doğum fizyolojik eğitimi, fetüsün duygu ve algısının farkında olunması, bağlanma kavramı, zihinsel imgeleme ve bağlanma davranışı, fetüsle iletişim, anksiyete kontrolü, olumsuz düşünceler, uygun uyku düzeni, egzersiz ve beslenmeyi içerir (Shin, Park ve Kim, 2006). Bağlanma oluşumu ve hamile kadınların anksiyete azaltma tekniklerinden kaynaklanan etkinin yanı sıra çoğu durumda bu tür tekniklerin grup eğitimi, kişinin zihinsel durumları ve ruhu üzerinde anlamlı bir etkiye sahip olan kadınların bir araya gelmesini sağlar. Yeni bir sosyal ağa giren ve diğer annelerle tanışan kadınlar tarafından, bağlanma eğitiminin hamile kadınlara duygusal ve sosyal destek olma, tıbbi ve bakım hizmetlerinden daha iyi yararlanma şansı verdiği bildirilmiştir (Ferguson, Davis ve Browne, 2013).

Yoga uygulamast: Vücut farkındalığının artırılması, olumlu psikolojik etki ve yaşamdan memnuniyet ile ilişkilendirilmiştir (Williams, 2015). Yoga ve meditasyon uygulamaları annenin bedeninde meydana gelen değişimlere uyum sağlamasını, meditasyon sırasında karnına dokunarak bebeğiyle iletişime geçmesini sağlayarak yaşanan fizyolojik ve psikolojik stresörlerle baş edebilmesine yardımcı olur, anne-bebek bağlanmasını artırır. Gebeye kazandırdığı olumlu bakış açısı, duygusal olarak iyi hissetmesini ve genel anlamda sağlıklı hissetmesini sağlar. Bu olumlu psikolojik etki anne ve bebeğin iletişimini ve birlikteliğini güçlendirir (Satyapriya, Nagarathna, Padmalatha ve Nagendra, 2013). Başka bir çalışmada da esneme, nefes alma, meditasyon gibi yoga egzersiz eğitimleri uygulanmıştır. Yoga grubunda bağlanma ve psikolojik sağlık daha fazla artmıştır (Muzik, Hamilton, Rosenblum, Waxler ve Hadi, 2012). Bu çalışmalar göz önüne alındığında yoganın doğum sonu dönemde annenin yaşadığı stresin artırdığ 1 ve anne-bebek bağlanmasını artırdığı düşünülebilir. Yapılan bir çalışmada doğum sonrası dönemde yoga uygulamasının annelerde emzirme yeterliliğini ve maternal bağlanmayı artırdığı bulunmuştur (Koyuncu, 2019).

Sakin Gebelik Müdahalesi; Anksiyete belirtilerine yanıt vermenin alternatif yollarını öğretir ve farkındalık tekniklerini, bilişsel yaklaşımları, anksiyete hakkında eğitim vererek bilişsel çarpıtmaları düzenli uygulama yoluyla günlük yaşamda farkındalığın kullanımını teşvik etmek için ev ödevi içeren bir müdahale yöntemidir (Goodman ve ark., 2014). Gebelerde anksiyete tedavisinde kognitif terapi başarıyla uygulanmaktadır. Bilişsel terapiyle bireyin otomatik olumsuz düşüncelerini ve ilgili inançlarını tanımlamasına ve yeniden değerlendirmesine ardından mantıklı ve gerçekçi alternatif düşünceler bulmasına yardımcı olur. Aynı zamanda etkili problem çözme, stres yönetimi ve kişilerarası ilişki becerilerini öğretir (Vieten ve Astin, 2008). Yapılan bir çalışmada bilişsel terapinin anksiyeteyi ve doğum korkusunu azaltarak anne-bebek bağlanmasının kalitesini ve annenin iyi oluş durumunu artırdığı bulunmuştur (Sockol, 2015).

\section{Literatür Çerçevesinde Önleyici Müdahale Yöntemlerine Yönelik Öneriler}

Bebek ve birincil bakım veren kişi arasında oluşan ilk bağlanma ilişkisinin kalitesi bebeğin ilerideki kendisi ve başkaları ile ilgili algılarının temelini oluşturmaktadır. $\mathrm{Bu}$ nedenle de bakım veren kişinin ilk yıllarda kritik önem 
taşıyan bu ilișkinin önemi ve bebek bakımı hakkında bilinçlendirilmesi, özellikle salgın döneminde stresle başa çıkma tarzları konusunda eğitilmesi çok önemlidir. Literatürde yer alan önleyici müdahale yöntemleri doğrultusunda Türkiye'de uygulanabilecek birçok teknik bulunmaktadır.

Hamileliğin neden olduğu anatomik, fizyolojik ve hormonal değişiklikler ve bu değişikliklerin anne bedeni ve zihni üzerindeki etkisi hakkında eğitimin düzenlenmesi salgın döneminde zor olacağından bu bilgilerin yer aldığ 1 animasyonlu broşürler hazırlanarak doğum odalarına konulabilir. $\mathrm{Bu}$ broşürün içinde anlaşılır bir dil kullanılarak bağlanma kuramı ve gebelikte yüksek bağlanmanın yararları, embriyo gelişimi, beslenme ve bakımın anne-fetüs sağlığı üzerindeki etkisi, egzersiz yapmak, kocanın bir destekçi olarak rolüne aşinalık kazanmasının önemini içeren bilgilerin eklenmesinin, farkındalığı artıracağı düşünülmektedir. Yapılan bir çalışmada eğitim broşürü ile eğitim ve bakım verilen, birden fazla doğum yapmış (multipar), doğum yöntemi vajinal olan kadınların, eğitim ve bakım almayan, ilk kez doğum yapan (primipar), doğum yöntemi sezaryen olan kadınlara göre doğum sonrası anksiyete düzeyleri daha düşük bulunmuştur (Yıldız ve Akbayrak, 2014). Gebeliğe özgü nöroendokrin faktörler sadece kadınları etkilese de ebeveynlikle ilişkili bilişsel ve durumsal risk faktörleri babaları da etkilemektedir (Fairbrother ve Abramowitz, 2007).

Gebelik, doğum, lohusalık ve yeni doğanın bakımı ile ilgili bilgiler içeren multidisipliner bir doğuma ve anneliğe hazırlık programına gönderilen hamile kadınların anksiyete puanlarının düştüğü, kontrol grubunun ise puanlarının arttığı bulunmuştur. Gebeliğin sonundaki kaygı düzeyleri ile vajinal doğum, gebelik yaşı negatif bir korelasyon göstermiştir. Program daha düşük anksiyete seviyesi, daha fazla vajinal doğum ve yeni doğanların daha kısa hastanede kalış süresi ile ilişkilendirilmiştir (Miller, Chu, Gollan ve Gossett, 2013). Türkiye'de de böyle bir içeriğe sahip bir program profesyoneller tarafından uygulanabilir biçim hazırlanabilir.

Yapılan bir araştırmada anne farkındalığının stres değişkeni yoluyla annenin bebeğiyle daha yakın ilişki kurmasını doğrudan ve dolaylı olarak etkilediği bulunmuştur (Tsao, Hsing, Wang ve Guo, 2019). Bağlanmayı artırmak için doğum öncesi bakım, farkındalık, gebelikteki semptomlar ve stresi azaltma ile birleştirilerek daha başarılı olabilir. Artan farkındalık seviyeleri, kadınların anneliğe daha olumlu yaklaşmalarına ve sağlık durumlarını iyileştirmelerine yardımcı olabilir, doğum sonrası yaşanan psikolojik semptomları iyileştirebilir. Sağlı hizmeti sağlayıcıları, hamilelik sırasında annenin rolünü kazanma sürecini kolaylaştıran psikolojik adaptasyona duyarlı olmalıdır. Farkındalığa yönelik bir eğilim ve algılanan stres bağlanmanın gelişmesinde çok önemli bir faktördür. Kişinin hamilelik stresine karşı açık ve yargılayıcı olmayan bir tutum geliştirmesi ve sağlık pratisyenlerinin doğum öncesi bakım sırasında hamile kadınların farkındalık durumun tanıması anne-bebek arasındaki ilişkiyi ele almak açısından çok önemlidir. Hamilelikteki stres ve semptomlar doğum öncesi eğitim programları sırasında müdahalelere yatkındır. Erken müdahale için düşük farkındalığa sahip hamile kadınların özelliklerini bilmek fayda sağlayacaktır. Bağlanma konusun eğitim kurumlarında loğusa bakımı müfredatına dâhil edilmesi önerilmektedir. Doğum sonrası başlangıçlı ObsesifKompülsif Bozukluğun (OKB) semptomları konusunda anne adayları ve sağlık uzmanları eğitilmelidir. Hastanın acı çekmesini, aile fonksiyon bozukluğunu ve bebek gelişimi üzerindeki olumsuz etkilerini en aza indirmek için hastalık doğum sonrası erken dönemde taranmalı ve tedavi edilmelidir. Doğum sonrası OKB epidemiyolojisini değerlendirmek, fenomenolojisini ve klinik seyrini detaylandırarak bunların OKB olmayan kadınlarda OKB ile karşılaştırıldığında nasıl farklı olduğunu açıklamak için daha fazla araştırmaya ihtiyaç vardır. OKB semptomları tedavi edilebilir bir durumdur ancak süreçte sosyal, psikolojik, mesleki ve fiziksel refahı etkileyerek, bağlanma deneyimini (kritik olarak) çalma gücüne sahiptir. Farkındalık eksikliği etkili tedaviler olmasına rağmen ebeveyne ulaşmaz. Risk altındaki ebeveynleri tespit etmek ve onları etkili bir biçimde yöneterek yaşam kalitelerini iyileştirmek ve bunun sonucunda ebeveynlik rollerini yerine getirmelerini sağlamak için farkındalık gereklidir (Rook, 2016).

Literatür BDT'nin hamile ve emzirirken ilaç almamayı tercih eden kadınlar için perinatal OKB'de potansiyel olarak yararlı ve kabule edilebilir bir tedavi olduğunu göstermektedir (Austin, Pavlovic, Leader, Saint ve Parker, 2005). Tedavinin yoğun olarak kısa bir zaman diliminde uygulanabilmesi küçük çocuklu kadınların tedaviye erişimini artırmada oldukça etkilidir. $\mathrm{Bu}$ da iyileşmenin daha kısa süreceği böylece ebeveynlik ve anne-bebek ilişkisi üzerindeki etkinin en aza indirilebileceği anlamına gelir (Glover ve O'Connor, 2002). Buradan yola çıkarak semptomlar hakkında bilgi vermek, suçluluk duygularını azaltmak, tedavi için bir mantık sağlamak ve tedaviye uyumu teşvik etmek amacıyla psiko-eğitim programları düzenlenebilir. Yapılan bir araştırma doğum eğitimi sınıflarına bilişsel davranışçı terapi tabanlı bir obsesif kompülsif semptomları önleme programının dahil edilmesinin potansiyel faydasını destekleyen sonuçlar bulmuştur. Eğitim grubundakilerin kontrol grubuna göre bilişsel çarpıtma seviyelerinin anlamlı derecede azaldığı bildirilmiştir (Sharma ve Sommerdyk, 2015). Gebelik sırasında veya doğum sonrasında obsesyonel problemlerin ilk başlangıcını yaşayan kadınlar semptomlarını bir rahatsızlığın parçası olarak kabul etmeyebilir ve yardım istemeyebilir. Kadın doğum uzmanları gebeliğin seyri sırasında ve doğum sonrası erken dönemde OKB semptomlarını aktif olarak taramalıdır. Sonuç olarak BDT hamile ve doğum sonrası kadınlar için OKB'nin ilk basamak tedavisi olarak önerilebilir. Hasta ve ailesi için destekleyici psikoterapi de BDT veya farmakoterapiye yararlı bir yardımcı olabilir. OKB hastaları genellikle aile üyelerini ritüellerine dâhil eder. Yeni annelerin bebeklerini sakatlamaktan korktukları için yeni doğanlarla yalnız kalamadıkları için işlerini kaybeden kocalara dair raporlar vardır. Destek ve eğitim hastanın hastalığını anlamada, ortaya çıkabilecek aile işlev bozukluğunu tersine çevirmede ve yeni doğanın bakımında aile için önemlidir. Doğum sonrası başlangıçlı OKB'nin etiyolojisi ve kesin insidans1 (epidemiyolojisi) ve yaygınlık oranları bilinmemektedir (Brandes, Soares ve Cohen, 2004). Yapılan bir çalışmada OKB'nin temelini oluşturduğu düşünülen önceden var olan işlevsiz inanç seviyeleri doğum sonrası obsesif kompülsif semptomların şiddetini öngörmüş ve anksiyetesi yüksek ebeveynlerin doğum sonrasında şiddetli obsesif kompülsif semptomlar gösterdiği ortaya konmuştur (House ve ark., 2016). Ayrıca 
stres ve sürekli kaygı bilişsel müdahaleleri olumsuz bir şekilde yorumlama eğilimini artırmaktadır. Maruz kalma, yanıtın önlenmesi ve BDT tedavisi obsesyonların ve kompülsiyonların gelişiminde rol oynadığ 1 belirlenen işlevsiz inanç türlerinin düzeltilmesinde etkilidir (McLean ve ark., 2001). Zorlayıcı davranışların etkisiyle başlangıçta bebekle geçirilen sinırlı zaman ve aynı zamanda azalan sosyal ve mesleki işlevselliğin yanı sıra yaşam kalitesindeki belirgin bir düşüş ebeveynlik becerisini hızla etkilemeye başlayacaktır (Goecke ve ark., 2012). Tedavi edilmeyen bu semptomlar kadınların annelikten zevk almasını etkileyecek, uzun sürede duygu durum ve anksiyete bozukluklarına karșı daha kırılgan hale getirecektir (Muzik ve ark., 2013).

Avustralya'daki az sayıda merkez, belirti taşıyan kadınların tespiti için doğum öncesi psikososyal tarama protokolleri geliştirmiştir. Yapılan bir çalışma hem gebelikte hem de doğum sonrası OKB ve anksiyete için BDT kullanımı desteklemiştir. Mevcut kanıtların en iyi yorumu birinci basamak tedavi stratejisini temsil edebileceği ve BDT'nin emziren ve hamile kadınlara önerilen ilk tedavi olması gerektiğidir (Marchesi ve ark., 2016).

Gebelikte anksiyete bozukluğunun tedavisinde BDT'nin etkinliğini ve gebelik yaşı ve doğum ağırlığı üzerine etkilerini değerlendiren bir diğer çalışmada; tedavi sonrası anksiyete semptomlarının seviyeleri başlangıç seviyesinden önemli ölçüde daha düşük bulunmuştur. BDT grubu ile tedavi edilmeyen grup arasında gebelik yaş1 veya yeni doğan doğum ağırlığı açısından önemli bir fark bulunmamıștır. BDT'nin hamilelik sırasında ve sonrasında anksiyete semptomlarında güvenli ve etkili bir tedavi olduğu söylenilebilir (Uguz ve Ak, 2021).

Beck'in bilişsel modeli de müdahale için hedeflenebilecek anksiyete risk faktörlerinin belirlenmesinde bir çerçeve sağlar. Bu modele göre bilişsel önyargılar potansiyel olarak stresli yaşam olayları bağlamında anksiyete belirtilerine karşı bir kırılganlık sağlar. Bilişsel modellerde yaşam olayları ile duygusal deneyimler arasındaki ilişki bilişsel süreçler aracıllğ̆yla gerçekleştirilir. Anksiyete gibi uyumsuz duygusal tepkiler bu bilişsel süreçlerdeki sistematik önyargılardan kaynaklanır. Anksiyete bozukluğu olan bireyler arasında bilişsel sıklıkla artan tehdit ve tehlike algıları ile karakterize edilir (Beck, 2008). Yapılan bir araştırma olumsuz bilişsel önyargıların gebelikte ve doğum sonrası dönemde anksiyete ile ilişkili olduğunu göstermiştir (Cooper, Murray, Wilson ve Romaniuk, 2003). Bu önyargılara BDT yoluyla yanıt verilebilir.

Ebeveynler arasındaki takıntılı sorunları etkili bir şekilde tahmin edebilecek ve önleyebilecek programların geliştirilmesi, değerlendirilmesi ve uygulanması önerilebilir. Yapılan başka bir araştırmada travmatik yaşam olaylarının varlı̆̆ $\mathrm{OKB}$ semptomlarının şiddetindeki artı̧̧ ile ilişkili bulunmuştur (Cromer, Schmidt ve Murphy, 2007). Salgının büyük bir yaşam stresi olduğu düşünüldüğünde tedavide de yaşam streslerinin daha sistematik ele alınması gerekmektedir. OKB geliştirme riski taşıyan kadınlar için bilişsel davranışçı temelli önleme programlarının, doğum öncesi eğitim sınıflarına entegre edilmesi, doğumdan sonra anlaml düzeyde daha düşük obsesif-kompülsif özelliklerle ilişkilidir. Bu bilgi doğrultusunda salgın sırasında doğum öncesi ve sonrası obsesif-kompülsif semptomları önlemek için tedavi stratejileri geliştirilmelidir. Hamile kadınların psikolojik durumlarının taranması evrensel tarama programlarına entegre edilebilir (Timpano, Abramowitz, Mahaffey, Mitchell ve Schmidt, 2011). Hamile olan veya doğum sonras1 12 ay içinde olan 10 kadında perinatal anksiyeteyi ele almak için özel olarak tasarlanmış bilişsel davranışçı grup tedavisi programının etkililiğinin incelendiği bir araştırmada anksiyete bozukluğu olan kadınlar için 6 haftalık bir grup BDT programının tedavi öncesinden sonrasına kadar semptomları belirli ölçüde iyileştirdiği bulunmuştur (Green, Haber, Frey ve McCabe, 2015).

\section{Sonuç}

Covid-19 salgını perinatal kadınlar arasında kaygı ve stres düzeyini büyük ölçüde artırma potansiyeline sahiptir. Hastalığın korku ve psikolojik etkisi enfeksiyon kadar zararlı olabilir. Hamilelik de iyi bilinen köklü bir değişim dönemidir (Carter ve Kostaras, 2005). Yeterli zihinsel ve fiziksel sağlık; duygu durum bozuklukları için koruyucu bir faktördür ve bazı kadınlar için gebelik bazı psikiyatrik hastalıklara karşı savunmasızlığı artırabilir (Grigoriadis ve ark., 2018). İzolasyon, sosyal mesafe ve günlük yaşamdaki aşırı değişiklikler yeni anneler gibi savunmasız nüfus arasında psikolojik bozukluklara karşı daha açık hale gelebilecekleri düşünülebilir. $\mathrm{Bu}$ nedenle salgının psikolojik etkisini değerlendirmek büyük önem taşımaktadır. Covid-19 döneminin anne-bebek bağlanması üzerindeki etkilerini azaltmaya ve maternal bağlanmayı artırmaya yönelik önleyici müdahale yöntemlerinin incelendiği bu çalışmada literatürde öne çıkan teknikler ele alınmıştır. Bu teknikler yapılan çalışmalarla desteklenerek tartışılmıştır. Mevcut çalışmanın çıkarılan sonuçlarına göre sunulan önerilerin uygulanmasının Türkiye'de perinatal ruh sağlığının geliştirilmesinde ve doğum sonrası bakımın kalitesinin iyileştirilmesine yardımcı olabileceği düşünülmektedir. Sonuç olarak yeni ebeveyn olmak salgının da etkisiyle psikolojik bozukluklara karşı eşleri savunmasız hale getirmektedir. Bu nedenle sağlık hizmeti sağlayıcıları potansiyel doğum sonrası psikopatoloji konusundaki farkındalıklarını annelerin yanı sıra eşlere / partnerlere de yaymalıdır.

\section{Beyannameler}

Etik Onay ve Katılma İzni

Uygulanamaz.

\section{Yayın İzni}

Uygulanamaz.

\section{Veri ve Materyallerin Mevcudiyeti}

Uygulanamaz.

\section{Çıkar Çatışması}

Yazarlar çıkar çatışması olmadığını beyan eder.

\section{Finansman}

Uygulanamaz.

\section{Yazar Katkıları}

HÇS, makalenin konsept ve tasarımını oluşturmuştur.AK, literatür taraması, veri analizi ve yorumlama aşamasını yürütmüştür. HÇS, makalenin taslağını oluşturmuş, kritik 
revizyonu ve süpervizyonu üstlenmiştir. Tüm yazarlar makalenin son halini okumuş ve onaylamıştır.

\section{Kaynaklar}

Abasi, E., Tafazzoli, M., Esmaily, H. ve Hasanabadi, H. (2013). The Effect Of Mental-Fetal Attachment Education On Maternal Mental Health. Turkish Journal Of Medical Sciences, 43, 815820 .

Adam, K. E., Gunnar, R. M. ve Tanaka, A. (2004). Adult Attachment, Parent Emotion And Observed Parenting Behavior: Mediator And Moderator Models. Child Development, 75(1), $110-122$.

Akbarzadeh, M., Dokuhaki, A., Pishva, N. ve Zare, N. (2016). Teaching Attachment Behaviors To Pregnant Woman: A Randomized Controlled Trial Of Effects On Infant Mental Health From Birth To The Age Of Three Months. Annals Of Saudi Medicine, 36(3), 175-183.

Alan, H. ve Ege, E. (2013). The Influence Of Social Support On Maternal-Infant Attachment In Turkish Society. Anadolu Hemşirelik ve Sağlık Bilimleri Dergisi, 16(4), 234-240.

Alhusen, L. J. (2008). A Literature Update On Maternal-Fetal Attachment. Journal Of Obstetric, Gynecologic And Neonatal Nursing, 37(3), 317-328.

Amy, N. J. (2008). Promoting Maternal Confidence In The NICU. Journal Of Pediatric Health Care, 22(4), 254-257.

Arslan, F. ve Uzun, Ş. (2008). Hemşirenin Postnatal Eğitim ve Danışmanlık Hizmetlerinin İncelenmesi. Türkiye Klinikleri, 28, 736-742.

Austin, M. P., Pavlovic, H. D., Leader, L., Saint, K. ve Parker, G. (2005). Maternal Trait Anxiety, Depression And Life Event Stress In Pregnancy: Relationships With Infant Temperament. Early Human Development, 81, 183-190.

Beck, T. A. (2008). Bilişsel Terapi ve Duygusal Bozukluklar (A. Türkcan ve V. Öztürk, Çev.). İstanbul: Litera Yayıncılık.

Bellieni, V. C., Ceccarelli, D., Rossi, F., Buonocore, G., Maffei, M., Perrone, S. ve Petraglia, F. (2007). Is Prenatal Bonding Enhanced By Prenatal Education Courses? Minerva Ginecologica, 59(2), 125-129.

Bifulco, A., Figueiredo, B., Guedeney, N., Gorman, L. L., Hayes, S., Muzik, M., Dallay, G. E., Valoriani, V., Kammerer, H. M. ve Henshaw, A. C. (2004). Maternal Attachment Style And Depression Associated With Childbirth: Preliminary Results From A European And Us Cross-Cultural Study. British Journal Of Psychiatry, 184(46), 31-37.

Bilgin, Ç. N., Ak, B., Ayhan, F., Koçyiğit, Ö. F., Yorgun, S. ve Topçuoğlu, A. M. (2020). Effects Of Childbirth Education On Prenatal Adaptation, Prenatal And Maternal Attachment. The Anatolian Journal Of Family Medicine, 3(2), 128-135.

Boukydis, C. F., Treadwell, C. M., Black D. V., Boyes, K., King, M., Robinson, T. Ve Sokol, R. (2006). Women's Responses To Ultrasound Examinations During Routine Screens In An Obstetric Clinic. Journal Of Ultrasound In Medicine, 25(6), 721-728.

Bowlby, J. (1988). A Secure Base: Parent-Child Attachment And Healthy Human Development. United States Of America: Basic Books.

Brandes, M., Soares, N. C. ve Cohen, L. S. (2004). Postpartum Onset Obsessive-Compulsive Disorder: Diagnosis And Management. Archives Of Women's Mental Health, 7, 99-110.

Brandon, R. A., Pitts, S., Denton, H. W., Stranger, A. ve Evans, M. H. (2009). A History Of The Theory Of Prenatal Attachment. Journal Of Prenatal Perinatal Psychoogy Health, 23(4), 201-222.

Brockington, I. (2004). Postpartum Psychiatric Disorders. Lancet, 363, 303-310.
Buist, E. A., Milgrom, J., Barnett, E. W., Pope, S., Condon, T. J., Ellwood, A. D., Boyce, M. P., Austin, M. P. ve Hayes, B. (2002). To Screen Or Not To Screen-That Is The Question In Perinatal Depression. Medical Journal Of Australia, 177(7), 101-105.

Bussel Van, C. H., Spitz, B. ve Demyttenaere, K. (2009). Anxiety In Pregnant And Postpartum Women. An Exploratory Study Of The Role Of Maternal Orientations. Journal Of Affective Disorders, 114, 232-242.

Callister, C. L., Beckstrand, L. R. ve Corbett, C. (2011). Postpartum Depression And Help-Seeking Behaviors In Immigrant Hispanic Women. Journal Of Obstetric Gynecologic Neonatal Nursing, 40(4), 440-449.

Cooper, J. P., Murray, L., Wilson, A. ve Romaniuk, H. (2003). Controlled Trial of The Short-And Long-Term Effect Of Psychological Treatment Of Post-Partum Depression. I. Impact On Maternal Mood. British Journal Of Psychiatry, 182(5), 412419.

Cromer, R. K., Schmidt, B. N. ve Murphy, L. D. (2007). An Investigation Of Traumatic Life Events And ObsessiveCompulsive Disorder. Behavior Research And Therapy, 45, 16831691.

Çakır, L. ve Can, H. (2012). Gebelikte Sosyodemografik Değişkenlerin Anksiyete ve Depresyon Düzeyleriyle İlișkisi. The Journal Of Turkish Family Physician, 3(2), 35-42.

Çuvadar, Y. ve Çuvadar, A. (2021). Yenidoğanda Covid-19 Ve Bakım. Journal Of Health Professionals Research, 3(1), 38-41.

Diego, A. M., Field, T., Reif-Hernandez, M., Deeds, O., Ascencio, A. ve Begert, G. (2007). Preterm Infant Massage Elicits Consistent Increases In Vagal Activity And Gastric Motility That Are Associated With Greater Weight Gain. Acta Peadiatrica, 96(11), 1588-1591.

Dykes, K. ve Stjernqvist, K. (2001). The Importance Of Ultrasound To First-Time Mother's Thoughts About Their Unborn Child. Journal Of Reproductive And Infant Psychology, 19(2), 95-104

Elsenbruch, S., Benson, S., Rücke, M., Rose, M., Dudenhausen, J., Knackstedt-Pincus, M. K., Klapp, B. F. ve Arck, P. C. (2007). Social Support During Pregnancy: Effects On Maternal Depressive Symptoms, Smoking And Pregnancy Outcome. Human Reproduction, 22(3), 869-877.

Fairbrother, N. ve Abramowitz, S. J. (2007). New Parenthood As A Risk Factor For The Development Of Obsessional Problems. Behaviour Research And Therapy, 45, 2155-2163.

Faisal-Cury, A. ve Menezes, R. P. (2007). Prevalence Of Anxiety And Depression During Pregnancy. Archives Of Women's Mental Health, 10, 25-32.

Feldman, R. (2007). Parent-Infant Synchrony And The Construction Of Shared Timing; Physiological Precursors, Developmental Outcomes And Risk Conditions. Journal Of Child Psychology And Psychiatry, 48(3/4), 329-354, doi:10.1111/j.1469-7610.2006.01701.x.

Ferguson, S., Davis, D. ve Browne, J. (2013). Does Antenatal Education Affect Labour And Birth? A Structured Review Of The Literature. Women And Birth, 26(1), e5-e8.

Gabriel, M. A., Martin, I. L., Escobar, A. L., Villalba, E. F., Blanco, I. R. ve Pol, P. T. (2009). Randomized Controlled Trial Of Eary Skin-To-Skin Contact: Effects On The Mother And The Newborn. Acta Paediatrica, 99(11), 1630-1634. 
Glover, V. ve O'Connor, G. T. (2002). Effects Of Antenatal Stress And Anxiety: Implications For Development And Psychiatry. The British Journal Of Psychiatry, 180(5), 389-391.

Goecke, W. T., Voigt, F., Faschingbauer, F., Spangler, G., Beckmann, W. M. ve Beetz, A. (2012). The Association Of Prenatal Attachment And Perinatal Factors With Pre-And Postpartum Depression In First-Time Mothers. Archives Of Gynecology And Obstetrics, 286, 309-316.

Goodman, H. J., Guarino, A., Chenausky, K., Klein, L., Prager, J., Petersen, R., Forget, A. ve Freeman, M. (2014). CALM Pregnancy: Results Of A Pilot Study Of Mindfulness-Based Cognitive Therapy For Perinatal Anxiety. Archives Of Women's Mental Health, 17(5), 373-387.

Goulet, C., Bell, L., Tribble, S. C., Paul, D. ve Lang, A. (1998). A Concept Analysis Of Parent-Infant Attachment. Journal Of Advanced Nursing, 28(5), 1071-1081.

Green, M. S., Haber, E., Frey, N. B. ve McCabe, E. R. (2015). Cognitive-Behavioral Group Treatment For Perinatal Anxiety: A Pilot Study. Archives Of Women's Mental Health, 18(4), 631638.

Hart, R. ve McMahon, C. A. (2006). Mood State And Psychological Adjustment To Pregnancy. Archives Of Women's Mental Health, 9(6), 329-337.

Hazan, C. ve Shaver, P. (1987). Romantic Love Conceptualized As An Attachment Process. Journal Of Personality And Social Psychology, 52(3), 511-524.

Hazan, C. ve Shaver, R. P. (1994). Attachment As An Organizational Framework For Research On Close Relationships. Psychological Inquiry, 5(1), 1-22.

House, J. S., Tripathi, P. S., Knight, T. B., Morris, N., Newport, D. J. ve Stowe, N. Z. (2016). Obsessive-Compulsive Disorder In Pregnancy And The Postpartum Period: Course Of Illness And Obstetrical Outcome. Archives Of Women's Mental Health, 19(1), 3-10.

Huelin, R., Iheanacho, I., Payne, K. ve Sandman K. (2015). What Is A Name? Systematic And Non-Systematic Literature Reviews And Why The Distinction Matters. The Evidence Forum, https://www.evidera.com/wp-content/uploads/2015/06/Whats-ina-Name-Systematic-and-Non-Systematic-Literature-Reviewsand-Why-the-Distinction-Matters.pdf.

Jangjoo, S., Lotfi, R., Assareh, M. ve Kabir, K. (2019). Effects Of Counselling On Maternal-Fetal Attachment In Unwanted Pregnancy: A Randomized Controlled Trial. Journal Of Reproductive And Infant Psychology, 10, 1-11.

Kavlak, O. ve Şirin A. (2007). Anne ve Babaya Ait Bağlanma ve Hemşirenin Rolü. Ege Üniversitesi Hemșirelik Yüksek Okulu Dergisi, 23(2), 183-194.

Koyuncu, B. S. (2019). Postpartum Primipar Annelerde Yoganın Emzirme, Yeterlilik ve Maternal Bağlanma Üzerine Etkisi. (Doktora Tezi). İnönü Üniversitesi, Sağlık Bilimleri Enstitüsü, Malatya.

Marchesi, C., Ossola, P., Amerio, A., Daniel, B. D., Tonna, M. ve Panfilis, D. C. (2016). Clinical Management Of Perinatal Anxiety Disorders: A Systematic Review. Journal Of Affective Disorders, 190, 543-550.

Matthey, S., Barnett, B., Howie, P. ve Kavanagh, D. J. (2003). Diagnosing Postpartum Depression In Mothers And Fathers: Whatever Happened To Anxiety? Journal Of Affective Disorders, 74(2), 139-147.

Mckee, M. D., Cunningham, M., Jankowski, R. B. ve Zayas, L. (2001). Health-Related Functional Status In Pregnancy: Relationship To Depression And Social Support In A MultiEthnic Population. Obstetrics And Gynecology, 97(6), 988-993.

McLean, D. P., Whittal, L. M., Thordarson, S. D., Taylor, S., Söchting, I., Koch, J. W., Paterson, R. ve Anderson, W. K. (2001).
Cognitive Versus Behavior Therapy In The Group Treatment Of Obsessive-Compulsive Disorder. Journal Of Consulting And Clinical Psychology, 69(2), 205-214.

McNamara, J., Townsend, L. M. ve Herbort, S. J. (2019). A Systemic Review Of Maternal Wellbeing And Its Relationship With Maternal Fetal Attachment And Early Postpartum Bonding. Plos One, 14(7), e0220032, https://doi.org/10.1371/journal.pone.0220032.

Miller, S. E., Chu, C., Gollan, J. ve Gossett, R. D. (2013). Obsessive-Compulsive Symptoms During The Postpartum Period. The Journal Of Reproductive Medicine, 58(3-4), 115-122.

Milligan, K., Atkinson, L., Trehub, E. S., Benoit, D. ve Poulton, L. (2003). Maternal Attachment And The Communication Of Emotion Through Song. Infant Behavior And Development, 26, $1-13$

Moore, R. E., Anderson, C. G., Bergman, N. ve Dowswell, T. (2012). Early Skin-To-Skin Contact For Mothers And Their Health Newborn Infants. The Cochrane Database Of Systematic Reviews, 16(5), CD003519.

Muzik, M., Hamilton, E. S., Rosenblum, L. K., Waxler, E. ve Hadi, Z. (2012). Mindfulness Yoga During Pregnancy For Psychiatrically At Risk Women: Preliminary Results From A Pilot Feasibility Study. Complementary Therapies In Clinical Practice, 18(4), 235-240.

Muzik, M., Bocknek, L. E., Broderick, A., Richardson, P., Rosenblum, L. K., Thelen, K.ve Seng, J. S. (2013). Mother-Infant Bonding Impairment Across The First Six Months Postpartum: The Primacy Of Psychopathology In Women With Childhood Abuse And Neglect Histories. Archives Of Women's Mental Health, 16(1), 29-38.

Neff, D. K. (2009). The Role Of Self-Compassion In Development: A Healthier Way To Relate To Oneself. Human Development, 52(4), 211-214.

Özcan, H. ve Elkoca A. (2020). Covid-19 Enfeksiyonu Ve Gebelik Üzerindeki Etkileri. Anadolu Kliniği Tıp Bilimleri, 25(1), 43-50.

Özkan, A. H., Keleş, A. ve Arık B. (2021). Anne-Bebek Bağlanmasında Covid-19 Yansımaları. Ulusal Hemşirelik Kongresi: Dünyada Ve Ülkemizde Covid-19 Pandemisinin Hemşireliğe Ve Hemşirelik Vizyonuna Etkileri, Yeni Yüzyıl Üniversitesi, İstanbul.

Öztürk, R. ve Saruhan, A. (2013). 1-4 Aylık Premature Bebeği Hastanede Tedavi Gören Annelerin Depresyon Ve Maternal Bağlanma İlişkisinin İncelenmesi. Hemşirelikte Araştırma Geliştirme Dergisi, 1, 32-47.

Rook, M. D. (2016). Consider The Relationship Between Obsessive-Compulsive Disorder And Childbearing And How The Condition Might Affect Early Parenting. Perinatal Psychiatry Prize Essay, 1-10.

Satyapriya, M., Nagarathna, R., Padmalatha, V. ve Nagendra, R. H. (2015). Effect Of Integrated Yoga On Anxiety, Depression And Well Being In Normal Pregnancy. Compelementary Therapies In Clinical Practice, 19(4), 230-236.

Sedgh, G., Singh, S. ve Hussain, R. (2014). Intended And Unintended Pregnancies Worldwide In 2012 And Recent Trends. Studies In Family Planning, 45(3), 301-314.

Sercekus, P. ve Baskale, H. (2016). Effects Of Antenatal Education On Fear Of Childbirth, Maternal Self-Efficacy And Parental Attachment. Midwifery, 34, 166-172.

Sharma, V. ve Sommerdyk, C. (2015). Obsessive-Compulsive Disorder In The Postpartum Period: Diagnosis, Differential Diagnosis And Management. Women's Health, 11(4), 543-552.

Shin, H., Park, J. Y. ve Kim, J. M. (2006). Predictors Of Maternal Sensitivity During The Early Postpartum Period. Journal Of Advanced Nursing, 55(4), 425-434. 
Smith, A. C., Levett, M. K., Collins, T. C., Armour, M., Dahlen, G. H. ve Suganuma, M. (2018). Relaxation Techniques For Pain Management In Labour. Cochrane Database Of Systematic Reviews, 3, CD009514, DOI:10.1002/14651858.CD009514.

Sockol, E. L. (2015). A Systematic Reviews Of The Efficacy Of Cognitive Behavioral Therapy For Treating And Preventing Prenatal Depression? Journal Of Affective Disorders, 177, 7-21.

Taylor, A., Atkins, R., Kumar, R., Adams, D. ve Glover, V. (2005). A New Mother To Infant Bonding Scale: Links With Early Maternal Mood. Archives Of Women's Mental Health, 8, $45-51$.

Timpano, R. K., Abramowitz, S. J., Mahaffey, L. B., Mitchell, A. M. ve Schmidt, B. N. (2011). Efficacy Of A Prevention Program Of Postpartum Obsessive-Compulsive Symptoms. Journal Of Psychiatric Research, 45(11), 1511-1517.

Tsao, M. C., Hsing, C. H., Wang, H. H. ve Guo, M. H. S. (2019). The Factors Related To Maternal-Fetal Attachment: Examining The Effect To Mindfulness, Stress And Symptoms During Pregnancy. Archives Of Nursing Practice And Care, 5(1), 001007.

Uguz, F. ve Ak, M. (2021). Cognitive- Behavioral Therapy In Pregnant Women With Generalized Anxiety Disorder: A Retrospective Cohort Study On Therapeutic Efficacy, Gestational Age And Birth Weight. Brazilian Journal Of Psychiatry, 43(1), 61-64.
Urech, C., Fink, S. N., Hoesli, I., Wilhelm, H. F., Bitzer, J. ve Alder, J. (2010). Effects Of Relaxation On Psychobiological Wellbeing During Pregnancy: A Randomized Controlled Trial. Psychoneuroendocrinology.

Vieten, C. ve Astin, J. (2008). Effects Of A Mindfulness-Based Intervention During Pregnancy On Prenatal Stress And Mood: Results Of A Pilot Study. Archives Of Women's Mental Health, $11,67-74$.

Williams, N. A. (2015). The Impact Of Mindfulness-Based Prenatal Yoga On Maternal Attachment. (Master Of Social Work). California State University, Stanislaus.

World Health Organization. (2020). Clinical Management Of Severe Acute Respiratory Infection (SARI) When Covid-19 Disease Is Suspected: Interim Guidance. https://apps.who.int/iris/handle/10665/331446.

Yıldız, D. ve Akbayrak, N. (2014). Doğum Sonrası Primipar Annelere Verilen Eğitim Ve Danışmanlık Hizmetlerinin Bebek Bakımı, Kaygı Düzeyleri Ve Annelik Rolüne Etkisi. Gülhane Tıp Dergisi, 56(1), 36-41. 